\title{
REVIEW
}

\section{Endovascular abdominal aortic aneurysm repair}

\author{
M G A Norwood, G M Lloyd, M J Bown, G Fishwick, N J London, R D Sayers
}

Postgrad Med J 2007;83:21-27. doi: 10.1136/pgmj.2006.051177

The operative mortality following conventional abdominal aortic aneurysm (AAA) repair has not fallen significantly over the past two decades. Since its inception in 1991, endovascular aneurysm repair (EVAR) has provided an alternative to open AAA repair and perhaps an opportunity to improve operative mortality. Two recent large randomised trials have demonstrated the short and medium term benefit of EVAR over open AAA repair, although data on the long term efficacy of the technique are still lacking. This review aimed at providing an overview of EVAR and a discussion of the potential benefits and current limitations of the technique.

See end of article for authors' affiliations

\section{Correspondence to:} Mr M G A Norwood, Vascular Surgery Group, RKCSB, Leicester Royal Infirmary, Leicester LE2 7LX, UK; drmikenorwood@ hotmail.com

Received 6 July 2006 Accepted 7 August 2006
A bdominal aortic aneurysms (AAAs) occur in about $5 \%$ of men aged over 50 years. The incidence appears to be increasing, partly as a result of the increasing age of the population and also because of greater diagnostic awareness. ${ }^{1-3}$ The natural history of an AAA is expansion at a rate of approximately $0.5 \mathrm{~cm}$ a year and eventual rupture, unless death from another cause supervenes. Most AAAs are asymptomatic unless rupture occurs, which presents with the classical triad of abdominal and back pain, hypovolaemic shock, and a pulsatile abdominal mass. The risk of rupture is related to size. AAAs greater than $5.5 \mathrm{~cm}$ in diameter have a significant risk of rupture, and elective repair is therefore indicated..$^{45}$

Elective open surgical repair of an AAA is a complex procedure with a 30 day mortality of approximately $5 \%$ and a major complication rate of $15-30 \%$, figures that have not changed significantly over the past 20 years. $^{6-8}$ The operative mortality increases significantly in medically unfit patients, and can be as high as $50 \%$, resulting in many high risk patients being denied surgical repair. ${ }^{8}$ The operative technique has changed very little since Dubost's original description in 1952, and involves exposure of the aneurysm through a trans- or retroperitoneal route, clamping of the aneurysm neck and iliac arteries, opening of the aneurysm sac, and insertion of a prosthetic graft.' The major risks during open elective repair are perioperative cardiac events (for example, myocardial infarction), but respiratory and renal failure are also common. ${ }^{6}$ It is difficult to predict which patients are at risk despite techniques such as noninvasive cardiac risk assessment with echocardiography and physiological scoring systems such as POSSUM (Physiological and Operative Severity Score for the enUmeration of Mortality)..$^{10}$ However, in surviving patients the long term durability of the technique is good; the annual rate of graft failure is in the region of $0.3 \%$ and in the vast majority of cases the graft will outlive the patient. 51112

A ruptured AAA (RAAA) accounts for about 7000 deaths a year in England and Wales, and the incidence is increasing. ${ }^{1}$ The overall mortality is at least $80 \%$, with near $50 \%$ mortality in patients who reach hospital alive. Despite advances in surgery, anaesthesia, and critical care, there has been little reduction in mortality over the past 40 years. ${ }^{13}$ Surgical repair of an RAAA is a formidable undertaking. The technical problems during surgery include difficulties with vascular control, avoiding damage to surrounding structures, and achieving haemostasis in coagulopathic patients. Despite this, most patients (85\%) survive surgery, but many die in the postoperative period from progressive multiple organ failure. ${ }^{14}$ The cause of multiple organ failure is unknown, but probably related to widespread activation of inflammatory pathways stimulated by major surgery, hypovolaemic shock, acidosis, hypothermia, and massive blood transfusion.

At the present time, there are two strategies that might reduce the overall mortality from AAA. These are screening and endovascular aneurysm repair (EVAR). Ultrasound screening of a population at risk (usually men over 65 years of age) has been shown to reduce the incidence of RAAA in a recent multicentred trial, but as yet there is no national screening programme in the UK. ${ }^{1}$ EVAR of elective (non-ruptured) AAAs has been performed in the UK since the early 1990s. More recently, several centres have also described their initial experience of repair of ruptured AAAs using EVAR. EVAR of elective AAAs is currently being evaluated by randomised trials; the early and intermediate term results of two of these-the UK Endovascular Aneurysm Repair (EVAR) and the Dutch Randomised Endovascular Aneurysm Management (DREAM) trials-have recently been reported in the Lancet and the New England Journal of Medicine, respectively. ${ }^{15-18}$ This article reviews the current role of EVAR in the treatment of this complex disease process.

\section{ENDOVASCULAR AAA REPAIR}

EVAR was first described in humans by Parodi et al in 1991. ${ }^{19}$ This minimally invasive technique can be performed under general or regional anaesthesia and involves the placement of a stent-graft inside

\footnotetext{
Abbreviations: AAA, abdominal aortic aneurysm; $C T$, computed tomography; DREAM, Dutch Randomised Endovascular Aneurysm Management (trial); EUROSTAR, European Collaborators on Stent Graft Techniques for Abdominal Aortic Aneurysm Repair; EVAR, endovascular aneurysm repair; RAAA, ruptured AAA
} 
Table 1 Favourable anatomical features for EVAR

\begin{tabular}{ll}
\hline Anatomical feature & Dimension \\
\hline Neck length & $>15 \mathrm{~mm}$ \\
Neck diameter & $<30 \mathrm{~mm}$ \\
Neck angulation & $<50^{\circ}$ \\
Neck mural thrombus & $<2 \mathrm{~mm}$ \\
External iliac artery diameter & $>7 \mathrm{~mm}$ \\
lliac angulation & $<90^{\circ}$ \\
Common iliac diameter & $<18 \mathrm{~mm}$ \\
\hline
\end{tabular}

the aneurysm sac through the common femoral arteries. The stent-graft is a prosthetic vascular graft, (typically made of Dacron or polytetrafluoroethylene), which is reinforced by metallic struts and has metallic stents at the ends that fixate to the arterial wall. The stent-graft is usually delivered into the aneurysm inside a sheath, manoeuvred into position under $x$ ray (fluoroscopic) guidance, and deployed by withdrawal of the sheath. Final fixation at the proximal and distal ends of the stent-grafts is usually achieved by inflating a balloon inside the stent-graft to ensure firm attachment to the arterial wall.

Over the past decade a number of UK vascular units have been performing EVAR, and extensive experience of patient selection, intraoperative technique, and postoperative problems has been acquired. Indeed, not all patients are suitable for EVAR, and certain anatomical criteria must be satisfied in order for EVAR to be performed successfully. Several studies have shown that about $50 \%$ of patients with AAA are suitable for EVAR based upon anatomical and technical criteria, ${ }^{20-22}$ but this figure is likely to increase as stent-graft technology improves. Suitability is usually determined by a preoperative contrast enhanced computed tomography (CT) scan, or less frequently, angiography. ${ }^{23-25}$ Modern spiral CT scanners and, more recently, multidetector (multislice) scanners, allow accurate assessment of aortic morphology and the size of the stent-graft required by the rapid acquisition of thin axial slice ( $1-3 \mathrm{~mm}$ cut) images and two- and three-dimensional angiographic reconstructions. The anatomical criteria required for EVAR have been developed and refined over the years (table 1), but the underlying principles remain: the arterial anatomy proximal and distal to the aneurysm must allow firm fixation of the stent-graft to the arterial wall, and the iliac artery configuration must permit the stent-graft to access the aorta through the femoral arteries.

The precise anatomical requirements for each design of stentgraft differ but, in general, the proximal aneurysm neck (nondilated segment of aorta between the renal arteries and the aneurysm) should be free of thrombus, have adequate length, limited diameter, and limited angulation. ${ }^{26}$ The iliac arteries should be of sufficient calibre to allow the stent-graft to be introduced, should not be tortuous, and have minimal calcification. ${ }^{26}$ Attempted EVAR in the presence of unfavourable anatomy predisposes to intraoperative failure or postoperative complications. ${ }^{27}$ Although not considered an absolute contraindication to EVAR, patients with larger AAA have been found to be more likely to experience adverse outcomes. ${ }^{28-30}$

Historically, the early stent-grafts were tubular, single body aorto-aortic devices that fixed to the aortic wall proximally, and to the aneurysm sac distally. ${ }^{31}$ However, a high incidence of complications, particularly attachment site failure and distal migration of the stent-graft, has rendered these devices almost obsolete. ${ }^{32}$ Most stent-grafts currently in use are either bifurcated aorto-iliac grafts or straight aorto-monoiliac grafts. They are either unitary (one piece) or modular (composite) devices. If a monoiliac device is employed, the contralateral iliac artery is thrombosed (radiologically) and a femoro-femoral crossover graft is performed in order to perfuse the contralateral leg. Stent-graft design has rapidly evolved over the past decade, often in response to the identification of specific design related flaws and there has been a consistent trend towards newer devices outperforming their predecessors. ${ }^{28}{ }^{33}$ There is continuing research directed towards designing stent-grafts that will be able to contend with anatomical features that currently preclude or increase the risk of EVAR, with the aim of increasing the numbers of patients in whom EVAR can be performed. Fenestrated stent-grafts that extend above the renal arteries with holes placed over the ostia of the renal, superior mesenteric and coeliac arteries are being developed and will allow treatment of short necked or suprarenal AAAs. ${ }^{34} 35$ Flexible devices that can follow the contour of the aneurysm neck may be able to treat AAA with marked neck angulation, and smaller devices may be able to navigate narrow or tortuous iliac arteries.

\section{Existing research and continuing trials in EVAR}

In the past 15 years, there has been a large amount of research dedicated to EVAR. This research has largely consisted of either small studies investigating specific aspects of EVAR (usually in direct comparison with conventional AAA repair) or large national multicentre trials comparing EVAR with conventional AAA repair. The smaller studies have provided some convincing evidence that the minimally invasive nature of EVAR in conjunction with obviation of the need for laparotomy and complex abdominal dissection, results in less physiological insult than open AAA repair. Biological markers of inflammatory pathways and stress responses such as proinflammatory cytokines, adrenaline, cortisol, and complement activity are reduced. ${ }^{36-38}$ There is convincing evidence that EVAR is associated with reduced cardiac, respiratory, and renal complications, reduced need for blood transfusion and analgesia, shorter duration of surgery and postoperative hospital stay, lower need for intensive care, a faster return to normal function, and lower infection rates. ${ }^{16}{ }^{32} 39-43$

Until earlier this year, in the absence of evidence from large national randomised controlled trials, information on the efficacy of EVAR relied upon observational case series and data from large voluntary registries, such as the UK Registry for Endovascular Treatment of Aneurysms (RETA), and in particular, the European Collaborators on Stent Graft Techniques for Abdominal Aortic Aneurysm Repair (EUROSTAR) Registry. ${ }^{44} 45$ EUROSTAR is a voluntary registry that has been prospectively collecting data on EVAR procedures performed in Europe since 1999, and has provided much of the current EVAR outcome data. ${ }^{45}{ }^{46}$ These sources have suggested that the initial operative mortality of EVAR was comparable to that of open AAA repair but has consistently fallen and may now be as low as $1 \% .^{33} 46-49$ However, early meaningful interpretation and comparison of the data from these registries and case series was difficult to make because of factors such as publication bias, lack of patient randomisation, the likelihood of a preponderance of patients with small aneurysms, the inclusion of patients considered unfit for open AAA repair, and patients with less challenging anatomy. ${ }^{26}$ 50-52

A number of controlled trials of EVAR against open AAA repair are currently in progress. In the United Kingdom there are two multicentre trials; EVAR 1 and EVAR 2, both of which started in 1999. EVAR 1 has randomised patients with an AAA $>5.5 \mathrm{~cm}$ who are medically and anatomically suitable for both open AAA repair and EVAR to undergo one or other procedure. The EVAR 2 trial (discussed later) randomised patients who are considered medically unfit for open AAA repair (but anatomically suitable for EVAR) to undergo EVAR or receive "best medical treatment". Between September 1999 and December 2003, EVAR 1 recruited 1082 patients from 41 centres. Also in Europe, the smaller Dutch DREAM trial randomised 345 
patients to either open AAA repair or EVAR. The short term (30 day mortality) outcome of these trials was published in 2004, with the EVAR 1 trial reporting a significantly improved 30 day mortality in patients undergoing EVAR compared with patients undergoing open AAA repair $(1.7 \% \vee 4.7 \%)^{15}$; the DREAM trial reported a similarly improved 30 day mortality in EVAR versus open AAA patients $(1.2 \% v 4.6 \%){ }^{16}$ The DREAM trial was, however, underpowered, with the result that improved mortality rates did not reach statistical significance. The DREAM trial made the point that when combining their results with EVAR 1, the resulting operative mortality of $5.8 \%$ for open AAA repair and $1.9 \%$ for EVAR, yields a risk ratio of 3.1. ${ }^{16}$

Following on from the initial data, during 2005 EVAR 1 published its three year mortality data, ${ }^{17}$ which demonstrated that all-cause mortality was similar in the two groups, but that there was a persistent reduction in aneurysm related deaths in the EVAR group ( $4 \% v 7 \%$ ). The results of EVAR 2 were also published in 2005, ${ }^{53}$ but no benefit was shown in patients undergoing EVAR compared with those receiving "best medical treatment". The underpowered DREAM trial has also published further survival data, ${ }^{18}$ but initial (30 day) perioperative survival advantage of EVAR over open AAA repair was not sustained after the first year. World wide, in addition to the UK EVAR trial and the Dutch DREAM trial, the French Aneurisme de l'aorte abdominale: Chirurgie versus Endoprothese (ACE) study and the United States Open Versus Endovascular Repair (OVER) study are yet to report.

Despite the potential survival benefit and perioperative advantage of EVAR over open repair, enthusiasm for EVAR has been tempered by a number of procedure-specific problems that may result in further hospital admissions and secondary interventions. These problems are endoleaks and other graftspecific problems. Recent data from the EUROSTAR Registry ${ }^{54}$ have shown that secondary intervention was required in $8.7 \%$ of patients at 12 months. The annual cumulative rate for secondary intervention was $6 \%, 8.7 \%, 12 \%$, and $14 \%$ at $1,2,3$, and 4 years, respectively, resulting in an annual mean secondary intervention rate of $4.6 \%$. This has meant that long term surveillance of EVAR patients is needed, with its associated cost and resource implications. This also has implications for the patient and needs to be thoroughly discussed when consenting for surgery and deciding between EVAR and an open procedure. Indeed, some younger patients opt for a conventional, open operation if they do not want to return for long term follow-up.

\section{Endoleak}

The primary objective of AAA treatment is to prevent aneurysm rupture, and to achieve this, arterial perfusion of the aneurysm sac must be prevented. Endoleak is a phenomenon unique to EVAR and is defined as continued blood flow within the aneurysm sac after graft placement. It affects between 10 and $50 \%$ of patients. ${ }^{40515556}$ The conventional classification of endoleak into types 1-4 (table 2) is based on the anatomical source of the blood entering the aneurysm sac. ${ }^{56} 57$

Type 1 endoleak is caused by blood flow into the aneurysm sac due to failure of the graft attachment to the aortic wall,

Table 2 Classification of endoleaks

\begin{tabular}{ll}
\hline Endoleak type & Cause \\
\hline 1 & Failure of graft attachment to artery \\
2 & Retrograde blood flow from patent arteries \\
3 & Graft fabric disintegration or graft separation \\
4 & Flow through fabric of graft \\
5 (endotension) & Sac pressurisation without evidence of endoleak \\
\hline
\end{tabular}

either at the proximal or distal end of the graft. The principal causes appear to be adverse aneurysm morphology such as a short or angulated neck or gradual neck dilatation, probably as a consequence of progression of the aneurysmal process. ${ }^{58}$ Type 2 endoleak, the most common variety, results from retrograde blood flow into the sac from patent lumbar, inferior mesenteric, hypogastric or accessory renal arteries. Type 3 endoleak results from blood flow through the graft due to fabric tear or through the junction sites between graft components. This was a particular problem with early grafts and appears to be less of a problem with the newer devices. Type 4 endoleak usually occurs in very thin grafts, the fabric of which becomes relatively porous and allows blood flow through the graft. In common with type 3 endoleaks, this appears to be less of a problem with the newer devices. Endotension, or type 5 endoleak is a curious phenomenon characterised by continued sac pressurisation without evidence of endoleak. ${ }^{59}{ }^{60}$ A number of theories to explain type 5 endoleaks have been proposed, including sac thrombus transmitting pressure or the presence of small undetectable endoleaks. ${ }^{59} 61$

Type 1 and type 3 endoleaks are of particular significance, as they frequently signify blood entering the aneurysm sac at systemic blood pressure, resulting in continued aneurysm expansion and risk of rupture. ${ }^{59}{ }^{62}{ }^{63}$ Consequently, they require early intervention, either by balloon angioplasty to improve apposition to the arterial wall landing zone, the insertion of additional stent-grafts or cuffs to extend graft coverage in the landing zone or conversion to open repair. ${ }^{33}{ }^{64}$ The significance of type 2 and type 4 endoleaks is unclear. ${ }^{40}$ In many cases they are probably of low pressure and are benign. However, management of this phenomenon is complicated by the finding that even thrombosed endoleaks can transmit systemic pressure and result in rupture. ${ }^{656}$ There is currently no consensus about the management of type 2 endoleaks. In some centres, routine intervention, usually in the form of percutaneous coil embolisation or laparoscopic ligation of feeding vessels, is undertaken, ${ }^{33}{ }^{67}$ although recently there has been a trend towards intervention only if there is radiological evidence of continued expansion of the aneurysm sac, indicating a possible increased risk of rupture..$^{33} 356768$ Current opinion is that the aneurysm sac size change is of greater significance than the presence of an endoleak. Type 4 endoleaks are usually treated conservatively.

\section{Morphological changes}

After EVAR, postoperative morphological changes in the aneurysm sac can occur. Sac shrinkage is seen as a reassuring sign of successful aneurysm exclusion from the circulation. However, this can be accompanied by shortening in the longitudinal axis, ${ }^{69}$ which has been found to predispose to stent-graft limb kinking ${ }^{69} 70$ or separation of modular components, leading to graft occlusion ${ }^{43}$ or type 3 endoleak. $^{71}$ Continued expansion of the aneurysm neck after EVAR is a cause of late proximal attachment site failure, ${ }^{72}$ graft migration, and risk of rupture. ${ }^{46}$ The graft therefore has to cope with these morphological changes even after successful EVAR. It is expected that newer fenestrated grafts with suprarenal extension will be better able to survive these morphological changes. ${ }^{73}$

\section{Graft migration}

Distal migration of the stent-graft results from an attachment site failure and is a cause of late type 1 endoleak, graft occlusion, and aneurysm rupture. ${ }^{46}$ This was a significant problem with early aorto-aortic devices and the use of bifurcated or aorto-monoiliac grafts has reduced the incidence of migration. It is predicted that grafts with suprarenal fixation or extension will further reduce the risk. 


\section{Structural failure}

Failure of stent-graft components, particularly metal strut breakage and fabric failure, has been reported, and is usually visible on a plain abdominal radiograph. Significant problems have been identified with early proprietary devices, including hook fractures with the EVT device ${ }^{74}$ fabrication flaws with the Min Tec Stentor graft, loose ligatures on the Stentor endografts, and suture breakage in the Vanguard grafts, ${ }^{75}$ leading to withdrawal or modification of the affected devices.

\section{Rupture}

Rupture is a recognised complication of EVAR, with an incidence of between 1 and $1.5 \%$ a year, equivalent to the rupture risk of untreated AAA $<5.5 \mathrm{~cm} .{ }^{46}{ }^{76}$ The EUROSTAR Registry reported rupture in 34 out of 4291 patients. ${ }^{77}$ However, most of these ruptures occurred in patients with early generation grafts, although aneurysm related death after EVAR, excluding that for withdrawn devices, is still $0.6-0.7 \%$ annually. ${ }^{78}$ Worryingly, although type 1 and type 3 endoleaks and graft migration are predictors of increased risk of rupture, rupture can still occur occasionally in patients with no evidence of endoleak or previously increasing sac size. ${ }^{46} 79$

\section{Continued surveillance and need for further intervention}

The risk of the postoperative complications detailed above necessitates continued radiological surveillance of patients after EVAR, with yearly abdominal CT and plain abdominal radiographs. ${ }^{56}$ Complications such as endoleak can develop late in patients with normal early CT scan appearance, ${ }^{43}$ and as no definitive long term follow up data are available it is unclear how long postoperatively endoleak remains a risk. In most centres CT scans with contrast enhancement are performed before the patient is discharged from hospital, and at 6 and 12 months postoperatively, followed by lifelong annual scans. Clearly, patients need to be aware of this and accept the need for continued surveillance and possibly further procedures after EVAR, as poor compliance is associated with risk of rupture. ${ }^{77}$ Although graft failure, para-anastomotic aneurysm, and AAA rupture can follow open AAA repair, these occurrences are sufficiently uncommon to justify no postoperative surveillance and in most cases open AAA repair can be regarded as a definitive procedure.

The incidence of postoperative complications currently necessitates further hospital admission and secondary intervention in approximately $14 \%$ of patients over four years after EVAR. ${ }^{54}$ Despite this relatively frequent occurrence, approximately $80 \%$ can be treated with percutaneous radiological techniques. ${ }^{42} 80$ The concept of emphasising the "second outcome success" has been advocated as the correct way for the surgeon and patient to regard EVAR. The primary objective of AAA repair is to prevent rupture, and the need for further minimally invasive procedures to achieve this should perhaps not be regarded as failure. ${ }^{75}$ Along with aneurysm rupture, the need to convert to open AAA repair is a true indicator of failure of EVAR. Open procedures such as graft replacement after EVAR are technically difficult and carry a high mortality, in the region of $20 \%{ }^{81-83}$ The EUROSTAR Registry reported that an early conversion to open repair is necessary in $2 \%$ of patients undergoing EVAR. ${ }^{62}$

\section{Cost}

The uncertainty surrounding long term outcome after EVAR means that the true cost of the procedure is unknown. It was hoped that the savings resulting from a shorter operating time, shorter length of hospital stay, reduced intensive care costs, fewer operative complications, and faster recovery and return to work might offset the initial cost of EVAR. However, the high cost of stent-grafts, additional radiological imaging, readmissions to hospital, adjuvant procedures, and prolonged patient surveillance mean that EVAR is probably, at present, more expensive than open repair. ${ }^{84-86}$ If, as envisaged, EVAR related complications become less common and competition among stent-graft manufacturers leads to cheaper devices the cost of EVAR may compare more favourably with that of open AAA repair.

\section{Role of EVAR in elderly or medically unfit patients}

Historically, many elderly or medically unfit patients with AAA have not been referred to a surgeon or have been denied open AAA repair because of a high predicted perioperative mortality. ${ }^{68}{ }^{87}$ However, even in patients with significant comorbidities who have large or symptomatic AAA this is a difficult decision to make as rupture leading to almost certain death is frequently imminent. The decreased physiological insult, lower operative morbidity and mortality associated with EVAR, feasibility of performing the procedure under local anaesthesia, and the lesser importance of long term stent-graft durability have resulted in enthusiasm for performing EVAR in this patient group. A number of centres offering EVAR have reported increasing numbers of patients with AAA referred and subsequently treated, a likely consequence of the growing awareness by physicians of the potential role of EVAR in patients at high risk for open AAA repair. ${ }^{21} 88$ Published case series have reported encouraging morbidity and mortality rates in elderly patients and those considered high risk or unfit for open AAA repair. ${ }^{89}{ }^{90}$ However, despite EVAR appearing to be an attractive proposition in these patients, the results of the recently published EVAR 2 trial have failed to show any benefit of EVAR over "best medical treatment". ${ }^{53}$ The trial demonstrated a $9 \% 30$ day mortality in the EVAR arm of the trial compared with a rupture rate of 9.0 per 100 patient years in the "no intervention" group. The mean hospital cost over four years in the EVAR group was also high ( $£ 13632)$ compared with the "no intervention" group (£4983).

\section{Role of EVAR in RAAA}

The less invasive nature and physiological advantages of EVAR over open AAA repair may be of particular benefit in patients with RAAA with deranged physiology and approaching extremis. Since the first report in 1994 that RAAA can be successfully treated with EVAR, ${ }^{91}$ a number of centres have reported their early results, raising the possibility that the technique may provide the first real opportunity to improve operative mortality significantly in RAAA. Although experience is still limited, Ohki et al reported performing EVAR in 20/25 patients with RAAA with two deaths, ${ }^{92}$ and Lee et al reported being able to perform EVAR in 13/17 consecutive patients with RAAA with a single death. ${ }^{33}$ This compares favourably with the near $50 \%$ in-hospital mortality of open AAA repair. ${ }^{13}$

A number of potential problems persist, however. To perform EVAR a CT scan is required to assess the suitability of the aneurysm for EVAR and to size the graft correctly. Initially, only patients with "stable" ruptures, who were haemodynamically stable underwent EVAR as it was felt that the delay in obtaining a CT scan, which would delay starting surgery, would be detrimental. However, it has been shown that almost $90 \%$ of patients with RAAA who reach hospital alive survive longer than 2 hours, and most centres performing EVAR have spiral CT scanners that allow a complete abdomen and chest CT scan to be performed within seconds and protocols to facilitate the transfer of patients with RAAA to theatre within about 25 minutes of admission. ${ }^{94}$ As a result even haemodynamically unstable patients are currently undergoing successful EVAR in specialist units. 


\section{Key references}

- Greenhalgh RM, Brown LC, Kwong GP, et al, EVAR trial participants. Comparison of endovascular aneurysm repair with open repair in patients with abdominal aortic aneurysm (EVAR trial 1), 30-day operative mortality results: randomised controlled trial. Lancet 2004;364:843-8.

- Prinssen M, Verhoeven EL, Buth J, et al, Dutch Randomized Endovascular Aneurysm Management (DREAM) Trial Group. A randomized trial comparing conventional and endovascular repair of abdominal aortic aneurysms. N Engl J Med 2004;351:1607-18.

- EVAR trial participants. Endovascular aneurysm repair versus open repair in patients with abdominal aortic aneurysm (EVAR trial 1): randomised controlled trial. Lancet 2005;365:2179-86.

- Blankensteijn JD, de Jong, SECA, Prinssen M, et al. Two year outcomes after conventional or endovascular repair of abdominal aortic aneurysms. N Engl J Med 2005;352:2398-405.

- EVAR trial participants. Endovascular aneurysm repair and outcome in patients unfit for open repair of abdominal aortic aneurysm (EVAR trial 2): randomised controlled trial. Lancet 2005;365:2187-92.

\section{CONCLUSION}

EVAR is a new technique, and represents a major advance in the treatment of AAA. It has undergone considerable refinement since its advent, and confers a number of advantages over open AAA repair, including no need for laparotomy, less postoperative pain, no need for routine intensive care, and shorter hospital stay. The initial results look promising, and although there is no difference in all-cause mortality between patients undergoing EVAR and open repair, there is now evidence that EVAR is associated with a persistent reduction in aneurysm related deaths over three years (EVAR 1). Longer term follow-up data are still awaited, and in common with all new techniques EVAR has its problems-namely, secondary stent related problems that require intervention, the need for long term follow-up and the associated cost. However, stentgraft technology is rapidly advancing, and many of the initially identified problems are now being overcome. We think that EVAR is here to stay and that patients who are anatomically suitable for EVAR should be offered the opportunity to make an informed choice between EVAR and open AAA repair.

\section{MULTIPLE CHOICE QUESTIONS (TRUE (T)/FALSE (F)); ANSWERS AT THE END OF REFERENCES}

1. The mortality from AAA repair has fallen significantly over the past 20 years.

2. EVAR can be performed under regional anaesthesia.

3. The long term benefit of EVAR over open AAA repair has been proved.

4. Type 1 endoleak is frequently caused by a patent inferior mesenteric artery.

5. EVAR can be used to treat RAAA.

\section{Authors' affiliations}

M G A Norwood, G M Lloyd, M J Bown, N J London, R D Sayers, Department of Vascular Surgery, The Leicester Royal Infirmary, Leicester, UK
G Fishwick, Department of Radiology, The Leicester Royal Infirmary, Leicester, UK

\section{REFERENCES}

1 Ashton HA, Buxton MJ, Day NE, et al. The Multicentre Aneurysm Screening Study (MASS) into the effect of abdominal aortic aneurysm screening on mortality in men: a randomised controlled trial. Lancet 2002;360:1531-9.

2 Naylor AR, Webb J, Fowkes FG, et al. Trends in abdominal aortic aneurysm surgery in Scotland (1971-1984). Eur J Vasc Surg 1988;2:217-21.

3 Samy AK, Whyte B, MacBain G. Abdominal aortic aneurysm in Scotland. Br J Surg 1994;81:1104-6.

4 The UK Small Aneurysm Trial participants. Mortality results for randomised controlled trial of early elective surgery or ultrasonographic surveillance for small abdominal aortic aneurysms. Lancet 1998;352:1649-55.

5 Lederle FA, Wilson SE, Johnson GR, Aneurysm Detection and Management Veterans Affairs Cooperative Study Group, et al. Immediate repair compared with surveillance of small abdominal aortic aneurysms. N Engl J Med 2002;346:1437-44.

6 Blankensteijn JD, Lindenburg FP, Van der Graaf Y, et al. Influence of study design on reported mortality and morbidity rates after abdominal aortic aneurysm repair. Br J Surg 1998:85:1624-30.

7 Ernst CB. Abdominal aortic aneurysm. N Engl J Med 1993;328:1 167-72.

8 Johnston KW. Multicenter prospective study of nonruptured abdominal aortic aneurysm. Part II. Variables predicting morbidity and mortality. J Vasc Surg 1989:9:437-47.

9 Dubost C, Allary M, Oeconomos N. Resection of an aneurysm of the abdominal aorta: reestablishment of the continuity by a preserved human arterial graft, with result after five months. AMA Arch Surg 1952;64:405-8.

10 Heller JA, Weinberg A, Arons R, et al. Two decades of abdominal aortic aneurysm repair: have we made any progress? J Vasc Surg 2000;32:1091-100.

11 Hallett JW Jr, Marshall DM, Petterson TM, et al. Graft-related complications after abdominal aortic aneurysm repair: reassurance from a 36-year populationbased experience. J Vasc Surg 1997;25:277-84.

12 Johnston KW. Nonruptured abdominal aortic aneurysm: six-year follow-up results from the multicenter prospective Canadian aneurysm study. Canadian Society for Vascular Surgery Aneurysm Study Group. J Vasc Surg 1994:20:163-70.

13 Bown MJ, Sutton AJ, Bell PR, et al. A meta-analysis of 50 years of ruptured abdominal aortic aneurysm repair. Br J Surg 2002;89:714-30.

14 Sayers RD, Thompson MM, Nasim A, et al. Surgical management of 671 abdominal aortic aneurysms: a 13 year review from a single centre. Eur J Vasc Endovasc Surg 1997;13:322-7.

15 Greenhalgh RM, Brown LC, Kwong GP, et al, Comparison of endovascular aneurysm repair with open repair in patients with abdominal aortic aneurysm (EVAR trial 1), 30-day operative mortality results: randomised controlled trial. Lancet 2004;364:843-8.

16 Prinssen M, Verhoeven EL, Buth J, Dutch Randomized Endovascular Aneurysm Management (DREAM) Trial Group, et al. A randomized trial comparing conventional and endovascular repair of abdominal aortic aneurysms. N Engl J Med 2004;351:1607-18.

17 EVAR trial participants. Endovascular aneurysm repair versus open repair in patients with abdominal aortic aneurysm (EVAR trial 1): randomised controlled trial. Lancet 2005;365:2179-86.

18 Blankensteijn JD, de Jong SECA, Prinssen $M$, et al. Two year outcomes after conventional or endovascular repair of abdominal aortic aneurysms. NEngl J Med 2005;352:2398-405

19 Parodi JC, Palmaz JC, Barone HD. Transfemoral intraluminal graft implantation for abdominal aortic aneurysms. Ann Vasc Surg 1991;5:491-9.

20 Brewster DC, Geller SC, Kaufman JA, et al. Initial experience with endovascular aneurysm repair: comparison of early results with outcome of conventional open repair. J Vasc Surg 1998;27:992-1003.

21 Wolf YG, Fogarty TJ, Olcott C IV, et al. Endovascular repair of abdominal aortic aneurysms: eligibility rate and impact on the rate of open repair. J Vasc Surg 2000;32:519-23.

22 Armon MP, Yusuf SW, Latief K, et al. Anatomical suitability of abdominal aortic aneurysms for endovascular repair. Br J Surg 1997;84:178-80.

23 Beebe HG, Kritpracha B, Serres S, et al. Endograft planning without preoperative arteriography: a clinical feasibility study. J Endovasc Ther 2000;7:8-15.

24 Broeders IA, Blankensteijn JD, Olree $M$, et al. Preoperative sizing of grafts for transfemoral endovascular aneurysm management: a prospective comparative study of spiral CT angiography, arteriography, and conventional CT imaging. J Endovasc Surg 1997:4:252-61.

25 Gorham TJ, Taylor J, Raptis S. Endovascular treatment of abdominal aortic aneurysm. Br J Surg 2004;91:815-27.

26 Carpenter JP, Baum RA, Barker CF, et al. Impact of exclusion criteria on patient selection for endovascular abdominal aortic aneurysm repair. J Vasc Surg 2001;34:1050-4.

27 Stanley BM, Semmens JB, Mai Q, et al. Evaluation of patient selection guidelines for endoluminal AAA repair with the Zenith Stent-Graft: the Australasian experience. J Endovasc Ther 2001;8:457-64.

28 Torella F. Effect of improved endograft design on outcome of endovascular aneurysm repair. J Vasc Surg 2004;40:216-21.

29 Ouriel K, Srivastava SD, Sarac TP, et al. Disparate outcome after endovascular treatment of small versus large abdominal aortic aneurysm. J Vasc Surg 2003;37:1206-12. 
30 Peppelenbosch N, Buth J, Harris PL, EUROSTAR Collaborators, et al. Diameter of abdominal aortic aneurysm and outcome of endovascular aneurysm repair: does size matter? A report from EUROSTAR. J Vasc Surg 2004;39:288-97.

31 Uflacker R, Robison J. Endovascular treatment of abdominal aortic aneurysms: a review. Eur Radiol 2001;11:739-53.

32 Faries PL, Briggs VL, Rhee JY, et al. Failure of endovascular aortoaortic tube grafts: a plea for preferential use of bifurcated grafts. J Vasc Surg 2002;35:868-73.

33 Holzenbein TJ, Kretschmer G, Thurnher S, et al. Midterm durability of abdominal aortic aneurysm endograft repair: a word of caution. J Vasc Surg 2001;33(suppl):S46-54.

34 Greenberg RK, Haulon S, O'Neill S, et al. Primary endovascular repair of juxtarenal aneurysms with fenestrated endovascular grafting. Eur J Vasc Endovasc Surg 2004;27:484-91

35 Verhoeven EL, Tielliu IF, Prins TR, et al. Frequency and outcome of reinterventions after endovascular repair for abdominal aortic aneurysm: a prospective cohort study. Eur J Vasc Endovasc Surg 2004;28:357-64.

36 Thompson JP, Boyle JR, Thompson MM, et al. Cardiovascular and catecholamine responses during endovascular and conventional abdominal aortic aneurysm repair. Eur J Vasc Endovasc Surg 1999;17:326-33.

37 Boyle JR, Goodall S, Thompson JP, et al. Endovascular AAA repair attenuates the inflammatory and renal responses associated with conventional surgery. $J$ Endovasc Ther 2000;7:359-71.

38 Thompson MM, Nasim A, Sayers RD, et al. Oxygen free radical and cytokine generation during endovascular and conventional aneurysm repair. Eur $J$ Vasc Endovasc Surg 1996;12:70-5.

39 Boyle JR, Thompson JP, Thompson MM, et al. Improved respiratory function and analgesia control after endovascular AAA repair. J Endovasc Surg 1997;4:62-5.

40 Zarins CK, White RA, Schwarten D, et al. AneuRx stent graft versus open surgical repair of abdominal aortic aneurysms: multicenter prospective clinical trial. $J$ Vasc Surg 1999;29:292-305.

41 Zeebregts CJ, Geelkerken RH, van der Palen J, et al. Outcome of abdominal aortic aneurysm repair in the era of endovascular treatment. Br J Surg 2004;91:563-8.

42 Elkouri S, Gloviczki P, McKusick MA, et al. Perioperative complications and early outcome after endovascular and open surgical repair of abdominal aortic aneurysms. J Vasc Surg 2004;39:497-505.

43 Carpenter JP, Baum RA, Barker CF, et al. Durability of benefits of endovascular versus conventional abdominal aortic aneurysm repair. J Vasc Surg 2002;35:222-8

44 Thomas SM, Gaines PA, Beard JD. Vascular surgical society of Great Britain and Ireland: RETA: the registry of endovascular treatment of abdominal aortic aneurysms. Br J Surg 1999;86:711

45 Harris PL, Buth J, Mialhe C, et al. The need for clinical trials of endovascular abdominal aortic aneurysm stent-graft repair: the EUROSTAR Project. EUROpean collaborators on Stent-graft Techniques for abdominal aortic Aneurysm Repair. J Endovasc Surg 1997;4:72-7.

46 Harris PL, Vallabhaneni SR, Desgranges P, et al. Incidence and risk factors of late rupture, conversion, and death after endovascular repair of infrarenal aortic aneurysms: the EUROSTAR experience. European Collaborators on Stent/graft techniques for aortic aneurysm repair. J Vasc Surg 2000;32:739-49.

47 Zarins CK, Shaver DM, Arko FR, et al. Introduction of endovascular aneurysm repair into community practice: initial results with a new Food and Drug Administration-approved device. J Vasc Surg 2002;36:226-32.

48 Pfammatter T, Lachat ML, Kunzli A, et al. Short-term results of endovascular AAA repair with the Excluder bifurcated stent-graft. J Endovasc Ther 2002;9:474-80.

49 Blum U, Voshage G, Lammer J, et al. Endoluminal stent-grafts for infrarenal abdominal aortic aneurysms. N Engl J Med 1997;336:13-20.

50 Collin J, Murie JA. Endovascular treatment of abdominal aortic aneurysm: a failed experiment. Br J Surg 2001;88:1281-2.

51 Buth J, Laheij RJ. Early complications and endoleaks after endovascular abdominal aortic aneurysm repair: report of a multicenter study. J Vasc Surg 2000;31:134-46.

52 May J, White GH, Waugh R, et al. Improved survival after endoluminal repair with second-generation prostheses compared with open repair in the treatment of abdominal aortic aneurysms: a 5-year concurrent comparison using life table method. J Vasc Surg 2001;33(suppl):S21-6.

53 EVAR trial participants. Endovascular aneurysm repair and outcome in patients unfit for open repair of abdominal aortic aneurysm (EVAR trial 2): randomised controlled trial. Lancet 2005;365:2187-92.

54 Hobo R, Bath J, EUROSTAR collaborators. Secondary interventions following EVAR using current endografts. A EUROSTAR report. J Vasc Surg 2006;43:896-902.

55 White GH, Yu W, May J. Endoleak - a proposed new terminology to describe incomplete aneurysm exclusion by an endoluminal graft. J Endovasc Surg 1996;3:124-5.

56 Wain RA, Marin ML, Ohki T, et al. Endoleaks after endovascular graft treatment of aortic aneurysms: classification, risk factors, and outcome. J Vasc Surg 1998;27:69-78.

57 White GH, Yu W, May J, et al. Endoleak as a complication of endoluminal grafting of abdominal aortic aneurysms: classification, incidence, diagnosis, and management. J Endovasc Surg 1997:4:152-68.

58 Hinchliffe RJ, Hopkinson BR. Current concepts and controversies in endovascular repair of abdominal aortic aneurysms. J Cardiovasc Surg (Torino) 2003;44:481-502.

59 Veith FJ, Baum RA, Ohki T, et al. Nature and significance of endoleaks and endotension: summary of opinions expressed at an international conference. J Vasc Surg 2002;35:1029-35.
60 White GH, May J, Petrasek P, et al. Endotension: an explanation for continued AAA growth after successful endoluminal repair. J Endovasc Surg 1999;6:308-15

61 Dalal S, Donlon M, Beard JD. Thrombosed abdominal aortic aneurysms. Do they need surveillance to prevent late rupture? Eur J Vasc Endovasc Surg $2001 ; 22: 570-2$

62 van Marrewijk C, Buth J, Harris PL, et al. Significance of endoleaks after endovascular repair of abdominal aortic aneurysms: the EUROSTAR experience. J Vasc Surg 2002;35:461-73.

63 Chuter TA, Faruqi RM, Sawhney R, et al. Endoleak after endovascular repair of abdominal aortic aneurysm. J Vasc Surg 2001;34:98-105.

64 Faries PL, Cadot H, Agarwal G, et al. Management of endoleak after endovascular aneurysm repair: cuffs, coils, and conversion. J Vasc Surg 2003;37:1155-61

65 Velazquez OC, Baum RA, Carpenter JP, et al. Relationship between preoperative patency of the inferior mesenteric artery and subsequent occurrence of type II endoleak in patients undergoing endovascular repair of abdominal aortic aneurysms. J Vasc Surg 2000;32:777-88.

66 Schurink GW, van Baalen JM, Visser MJ, et al. Thrombus within an aortic aneurysm does not reduce pressure on the aneurysmal wall. J Vasc Surg 2000;31:501-6.

67 Gorich J, Rilinger N, Sokiranski R, et al. Embolization of type II endoleaks fed by the inferior mesenteric artery: using the superior mesenteric artery approach. $J$ Endovasc Ther 2000;7:297-301.

68 Dattilo JB, Brewster DC, Fan CM, et al. Clinical failures of endovascular abdominal aortic aneurysm repair: incidence, causes, and management. J Vasc Surg 2002;35:1137-44.

69 Harris P, Brennan J, Martin J, et al. Longitudinal aneurysm shrinkage following endovascular aortic aneurysm repair: a source of intermediate and late complications. J Endovasc Surg 1999;6:11-16.

70 Gould DA, Edwards RD, McWilliams RG, et al. Graft distortion after endovascular repair of abdominal aortic aneurysm: association with sac morphology and mid-term complications. Cardiovasc Intervent Radiol 2000;23:358-63

71 Beebe HG, Cronenwett JL, Katzen BT, Vanguard Endograft Trial investigators, et al. Results of an aortic endograft trial: impact of device failure beyond 12 months. J Vasc Surg 2001;33(suppl):S55-63.

72 Matsumura JS, Chaikof EL. Continued expansion of aortic necks after endovascular repair of abdominal aortic aneurysms. EVT investigators. EndoVascular Technologies, Inc. J Vasc Surg 1998;28:422-30.

73 Anderson JL, Berce M, Hartley DE. Endoluminal aortic grafting with renal and superior mesenteric artery incorporation by graft fenestration. J Endovasc Ther 2001;8:3-15.

74 Rutherford RB. Problems with the dissemination of up-to-date information on the results of endograft repair for abdominal aortic aneurysm. J Vasc Surg 1999;29:1167-9.

75 Zarins CK. The limits of endovascular aortic aneurysm repair. J Vasc Surg 1999;29:1164-6.

76 Bernhard VM, Mitchell RS, Matsumura JS, et al. Ruptured abdominal aortic aneurysm after endovascular repair. J Vasc Surg 2002;35:1155-62.

77 Fransen GA, Vallabhaneni SR Sr, van Marrewijk CJ, EUROSTAR., et al. Rupture of infra-renal aortic aneurysm after endovascular repair: a series from EUROSTAR registry. Eur J Vasc Endovasc Surg 2003;26:487-93.

78 Lindholt JS. Endovascular aneurysm repair. Lancet 2004;364:818-20.

79 Alimi YS, Chakfe N, Rivoal E, et al. Rupture of an abdominal aortic aneurysm after endovascular graft placement and aneurysm size reduction. J Vasc Surg 1998;28:178-83.

80 Makaroun MS, Chaikof E, Naslund T, et al. Efficacy of a bifurcated endograft versus open repair of abdominal aortic aneurysms: a reappraisal. J Vasc Surg 2002;35:203-10.

81 Bockler D, Probst T, Weber $\mathrm{H}$, et al. Surgical conversion after endovascular grafting for abdominal aortic aneurysms. J Endovasc Ther 2002;9:111-18.

82 Cuypers PW, Laheij RJ, Buth J. Which factors increase the risk of conversion to open surgery following endovascular abdominal aortic aneurysm repair? The EUROSTAR collaborators. Eur J Vasc Endovasc Surg 2000;20:183-9.

83 May J, White GH, Yu W, et al. Conversion from endoluminal to open repair of abdominal aortic aneurysms: a hazardous procedure. Eur J Vasc Endovasc Surg 1997;14:4-1 1

84 Bertges DJ, Zwolak RM, Deaton DH, et al. Current hospital costs and Medicare reimbursement for endovascular abdominal aortic aneurysm repair. J Vasc Surg 2003;37:272-9.

85 Clair DG, Gray B, O'Hara PJ, et al. An evaluation of the costs to health care institutions of endovascular aortic aneurysm repair. J Vasc Surg 2000;32:148-52.

86 Patel ST, Haser PB, Bush HL Jr, et al. The cost-effectiveness of endovascular repair versus open surgical repair of abdominal aortic aneurysms: a decision analysis model. J Vasc Surg 1999;29:958-72.

87 Lederle FA. Risk of rupture of large abdominal aortic aneurysms. Disagreement among vascular surgeons. Arch Intern Med 1996;156:1007-9.

88 Zarins CK, Wolf YG, Lee WA, et al. Will endovascular repair replace open surgery for abdominal aortic aneurysm repair? Ann Surg 2000;232:501-7.

89 Jordan WD, Alcocer F, Wirthlin DJ, et al. Abdominal aortic aneurysms in "highrisk" surgical patients: comparison of open and endovascular repair. Ann Surg 2003;237:623-9

90 Biebl M, Lau LL, Hakaim AG, et al. Midterm outcome of endovascular abdominal aortic aneurysm repair in octogenarians: a single institution's experience. J Vasc Surg 2004;40:435-42. 
91 Yusuf SW, Whitaker SC, Chuter TA, et al. Emergency endovascular repair of leaking aneurysm. Lancet 1994;344:1645.

92 Ohki T, Veith FJ, Sanchez LA, et al. Endovascular grafts and other image-guided catheter-based adjuncts to improve the treatment of ruptured aortoiliac aneurysms. Ann Surg 2000;232:466-79.

93 Lee WA, Hirneise CM, Tayyarah M, et al. Impact of endovascular repair on early outcomes of ruptured abdominal aortic aneurysms. J Vasc Surg 2004;40:21 1-15.
94 Lloyd GM, Bown MJ, Norwood MG, et al. Feasibility of preoperative computer tomography in patients with ruptured abdominal aortic aneurysm: a time-todeath study in patients without operation. J Vasc Surg 2004;39:788-91.

\section{Clinical Evidence-Call for contributors}

ANSWERS

(1) $\mathrm{F},(2) \mathrm{T},(3) \mathrm{F},(4) \mathrm{F},(5) \mathrm{T}$

Clinical Evidence is a regularly updated evidence-based journal available worldwide both as a paper version and on the internet. Clinical Evidence needs to recruit a number of new contributors. Contributors are healthcare professionals or epidemiologists with experience in evidence-based medicine and the ability to write in a concise and structured way.

Areas for which we are currently seeking contributors:

- Pregnancy and childbirth

- Endocrine disorders

- Palliative care

- Tropical diseases

We are also looking for contributors for existing topics. For full details on what these topics are please visit www.clinicalevidence.com/ceweb/contribute/index.jsp

However, we are always looking for others, so do not let this list discourage you.

Being a contributor involves:

- Selecting from a validated, screened search (performed by in-house Information Specialists) epidemiologically sound studies for inclusion.

- Documenting your decisions about which studies to include on an inclusion and exclusion form, which we keep on file.

- Writing the text to a highly structured template (about 1500-3000 words), using evidence from the final studies chosen, within 8-10 weeks of receiving the literature search.

- Working with Clinical Evidence editors to ensure that the final text meets epidemiological and style standards.

- Updating the text every 12 months using any new, sound evidence that becomes available. The Clinical Evidence in-house team will conduct the searches for contributors; your task is simply to filter out high quality studies and incorporate them in the existing text.

If you would like to become a contributor for Clinical Evidence or require more information about what this involves please send your contact details and a copy of your CV, clearly stating the clinical area you are interested in, to CECommissioning@bmigroup.com.

\section{Call for peer reviewers}

Clinical Evidence also needs to recruit a number of new peer reviewers specifically with an interest in the clinical areas stated above, and also others related to general practice. Peer reviewers are healthcare professionals or epidemiologists with experience in evidence-based medicine. As a peer reviewer you would be asked for your views on the clinical relevance, validity, and accessibility of specific topics within the journal, and their usefulness to the intended audience (international generalists and healthcare professionals, possibly with limited statistical knowledge). Topics are usually 1500-3000 words in length and we would ask you to review between 2-5 topics per year. The peer review process takes place throughout the year, and out turnaround time for each review is ideally 10-14 days.

If you are interested in becoming a peer reviewer for Clinical Evidence, please complete the peer review questionnaire at www. clinicalevidence.com/ceweb/contribute/peerreviewer.jsp 